\title{
O processo de desmedicalização da assistência à mulher no ensino de enfermagem
}

\author{
THE PROCESS OF DEMEDICALIZATION OF WOMEN'S HEALTH IN NURSING EDUCATION \\ EL PROCESO DE DESMEDICALIZACIÓN DE LA ASISTENCIA A LA MUJER EN \\ LA ENSEÑANZA DE ENFERMERÍA
}

Octávio Muniz da Costa Vargens ${ }^{1}$, Jane Márcia Progianti ${ }^{2}$

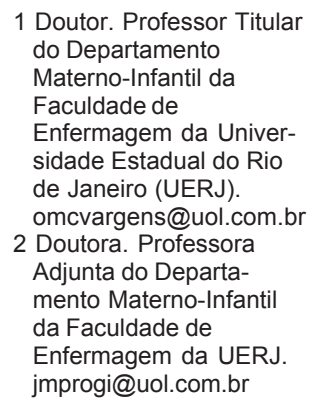

\author{
RESUMO \\ Este trabalho tem por objetivo \\ apresentar as estratégias \\ pedagógicas de \\ desmedicalização da \\ assistência no ensino da \\ enfermagem na saúde da \\ mulher adotadas na \\ Faculdade de Enfermagem da \\ UERJ. Contextualiza o ensino \\ na área e apresenta, à luz dos \\ conceitos de Pierre Bourdieu, \\ três esferas de atuação \\ discente e docente neste \\ processo.
}

\section{PALAVRAS-CHAVE}

Educação em enfermagem.

Saúde da mulher.

Enfermagem obstétrica.

Medicalização.

\begin{abstract}
This objective of this study is to present the pedagogic strategies adopted by the Rio de Janeiro State University Nursing School (UERJBrazil) for the demedicalization of care in nursing education in women's health. It presents the context of teaching in this area of knowledge. It also presents, from the perspective of concepts by Pierre Bourdieu, three spheres of students' and teachers' performance in this process.
\end{abstract}

\section{KEYWORDS}

Education nursing.

Women's health.

Obstetric nursing.

Medicalization.

\section{RESUMEN}

Este trabajo tuvo como objetivo presentar las estrategias pedagógicas adoptadas por la Facultad de Enfermería de la Universidad del Estado de Río de Janeiro (UERJ - Brasil), para la desmedicalización de la asistencia y de la enseñanza de enfermería en la salud de la mujer. El artículo presenta el contexto de la enseñanza en esta área del conocimiento. También presenta, bajo la perspectiva de los conceptos de Pierre Bourdieu, tres esferas de actuación del estudiante y del maestro en este proceso.

\section{PALABRAS CLAVE}

Educación en enfermería. Salud de las mujeres. Enfermería obstétrica. Medicalización. 


\section{INTRODUÇÃO}

O presente trabalho tem o objetivo de apresentar as estratégias pedagógicas de desmedicalização da assistência e do ensino da enfermagem na saúde da mulher. Tal fenômeno tomou força no Departamento de Enfermagem Materno-Infantil (DEMI) da Faculdade de Enfermagem da UERJ, antiga Escola de Enfermagem Rachael Haddock Lobo, no final da década de 90. Este período correspondeu ao processo de construção do novo currículo acadêmico, orientado pela teoria crítica, cujas concepções filosóficas valorizam a dialética e a transformação da realidade.

$\mathrm{Na}$ implementação do currículo construído pela equipe docente e por representantes discentes, o princípio central seguido foi a convicção de que não se queria mais o paradigma biomédico como norteador das práticas docentes da enfermagem na atenção à mulher. Isto significava uma desconstrução paralela de alguns conceitos na enfermagem obstétrica e na enfermagem ginecológica no âmbito desta Instituição acadêmica.

No entanto, sabíamos que a substituição de paradigmas seria um processo longo e trabalhoso, que envolveria muitos jogos de forças. Por isto mesmo deveria ser lento e gradativo, tendo pelo menos três esferas de transformação: a desmedicalização de nós mesmos, a do currículo no que se referia aos conteúdos e programas da área de saúde da mulher incluindo as estratégias de ensino, e por fim, a desmedicalização dos alunos.

\section{AS TRÊS ESFERAS DA DESMEDICALIZAÇÃO}

Para compreendermos melhor o que significa desmedicalizar, se faz necessário compreender que o processo de medicalização da sociedade é percebido de diversas maneiras. A primeira delas pode ser entendida como uma extensão da prática médica através do cuidado médico individual, que acompanhou o processo de implementação do modo capitalista de produção na sociedade ${ }^{(1)}$. A segunda, como um fenômeno antigo da medicina e que vem ligado às condições e possibilidades de instauração de um novo tipo de saber médico ${ }^{(2)}$. E ainda, como um fenômeno que torna a medicina controladora da sociedade através da invenção de desvios e patologias que desnaturalizam a vida cotidiana, deixando as pessoas em desarmonia com seu meio ${ }^{(3)}$.

Se tomarmos como base para reflexão, o conceito de poder simbólico de Pierre Bourdieu, podemos entender que o processo de medicalização implica também numa violência simbólica, onde o poder de fazer ver e de fazer crer, de produzir e de impor uma visão, depende da posição ocupada no espaço social ${ }^{(4)}$. Assim, quem tem um capital simbólico mais eficiente num dado campo (homens e médicos) impõe ao outro (mulheres e enfermeiras) um reconhecimento extorquido. Esta violência invisível e silenciosa se exprime através das declarações expressas por locutores de classes diferentes e através de coerções pontuais ou duradouras, a que os dominados se submetem, sem o uso da força física $^{(5)}$.

Contudo, a posição das mulheres frente ao processo de medicalização não foi propriamente a de vítimas. No início do século $\mathrm{XX}$, as mulheres reformistas das classes média e alta da sociedade tinham uma ideologia progressista, desejavam alterar as condições opressivas da vida feminina. A gravidez para elas não poderia mais ser encarada com fatalismo e passividade. Elas não queriam mais sentir a dor do parto e não queriam correr riscos. Além disto, para essas mulheres, parir com a assistência de um médico demonstrava o poder aquisitivo de seus maridos, que podiam pagar por seus serviços e pela moderna tecnologia ${ }^{(6)}$.

Ao contrário, as mulheres trabalhadoras, para as quais os riscos da gravidez e do parto eram intensificados pelas condições árduas do próprio trabalho e do estilo de vida, muitas vezes ficavam sem assistência médica e sem o acesso à tecnologia, necessitando ao parir de ajuda de curiosas ou parteiras ${ }^{(7)}$.

Deste modo, o processo de desmedicalização perpassa pelo desvelamento deste poder invisível que impregna as estruturas mentais das mulheres, que por não perceberem, não se reconhecem reprodutoras de uma estrutura de poder que as coloca em desvantagem em detrimento dos homens. As(os) docentes da Faculdade de Enfermagem foram formadas(os) neste modelo, viveram esta opressão, e de uma certa foram reprodutoras(es) desta estrutura. 
Octávio Muniz da C Vargens Jane Márcia Progianti
A desmedicalização vivida pelas(os) docentes foi resultante de seu próprio envolvimento com o pensamento feminista e com a incorporação da categoria gênero em sua prática e interpretação dos fenômenos relacionados à mulher e à enfermagem. A construção de conhecimentos buscando o entendimento das relações de poder entre homens e mulheres, mulheres e mulheres na enfermagem e na medicina foi a tônica da produção destas(es) docentes por ocasião de suas pós graduações (Mestrado e Doutorado). A produção de um conhecimento acadêmico crítico, aliado a um capital cultural adquirido numa história de lutas anteriores pela ocupação de posição e espaços no campo gineco-obstétrico, constituiu-se em uma força que contribuiu para a tomada de decisão deste grupo, em romper com a corrente opressora, combatendo os efeitos da violência simbólica contida na medicalização.

A desmedicalização do currículo e dos programas de enfermagem desta escola, mostrou-se ser uma poderosa estratégia de luta no campo obstétrico, pois esta instituição, começou a instrumentalizar enfermeiras e enfermeiras obstétricas para questionarem a hegemonia e as pretensas verdades contidas no saber médico autoritário. Visava-se com isso o estabelecimento de relações menos assimétricas e o desenvolvimento de práticas que proporcionassem outras opções à clientela, que queríamos como sujeito das ações de saúde no campo gineco-obstétrico.

A desmedicalização da mulher aluna de enfermagem, encontrou uma forte aliada nas estratégias adotadas pelas(os) docentes no desenvolvimento do currículo. No início, ainda que de forma incipiente e baseado numa ideologia pedagógica medicalizada, as(os) docentes procuravam redefinir os conceitos e práticas assistenciais à mulher. Estas estratégias, que representavam verdadeiras frentes de ataque, compreendiam principalmente: o uso do referencial médico como forma de denúncia de dominação (desvelamento dos dispositivos de poder simbólico); o uso dos saberes femininos interdisciplinares como embasamento do fazer da enfermeira; a implementação de campos de estágio com um paradigma que reconhece práticas não médicas de assistência à mulher; $\mathrm{e}$ o fortalecimento da identidade da enfermeira obstétrica através do conhecimento de sua história, da história das mulheres e da história da parturição.

\section{AS ESTRATÉGIAS PEDAGÓGICAS DE DESMEDICALIZAÇÃO DA ALUNA DE ENFERMAGEM}

$O$ uso do referencial médico como forma de denúncia de dominação (desvelamento dos dispositivos de poder simbólico)

Esta estratégia se consistiu no estímulo à (re)leitura de textos médicos. Ao indicarmos os livros médicos como textos, apontávamos, ao mesmo tempo, para uma leitura crítica dos conceitos e dos saberes embutidos nestes mesmos discursos. Assim, por exemplo, ao evidenciarmos a demarcação do corpo da gestante com nomes médicos ${ }^{(a)}$, denunciamos alguns dispositivos simbólicos de dominação. Desta forma, ao desvelar a existência deste poder simbólico, seus efeitos deixam de existir.

Paralelamente à crítica dos textos médicos, foram inseridos no ensino mais dois tipos de literatura: uma que criticava os efeitos nocivos da intervenção médica na saúde da mulher e outra que tratava do pensamento feminino na arte de cuidar de mulheres. Com isso, passamos a discutir estratégias através das quais as mulheres pudessem obter o domínio de seus corpos e o resgate de uma prática sensível e intuitiva no cuidado.

\section{O uso dos saberes femininos fundamentando o fazer da enfermeira}

Este processo de crítica da literatura médica fundamental nos levou a outro âmbito literário privilegiado: os textos das ciências humanas e sociais. Este âmbito literário, associado ao resgate e à valorização de saberes acumulados na experiência das parteiras curiosas, das parteiras diplomadas e das enfermeiras, não eliminou o interesse da aluna pela materialização dos fazeres da enfermagem através da técnica, mas a aluna e $\mathrm{a}(\mathrm{o})$ docente passaram a exercê-la daquele modo, mais sensível e criterioso.

Com este arcabouço teórico, práticas menos invasivas e mais solidárias de assistência à mulher foram incentivadas e adotadas pelas(os) docentes e discentes da Faculdade.

\section{A implantação de campos de estágio em maternidades e hospitais}

Neste momento, para compreendermos melhor esta estratégia, será preciso lançar mão de um breve histórico, pois muito antes 
da mudança curricular nos anos 90, as(os) professoras(es) do DEMI, já lutavam para conquistar espaços nas instituições hospitalares de assistência à mulher.

Nos anos 70/80, nas primeiras tentativas nesta esfera, adotamos a estratégia de associação direta ao poder médico instituído, na figura dos diretores das instituições. Esta associação implicava em atuar no campo gineco-obstétrico à revelia das equipes médicas e de enfermagem da instituição, as quais embora cumprindo determinação superior de aceitar-nos, lançavam mão de todos os recursos disponíveis para resistir à nossa atuação. Ficou evidente que esta nossa aliança com o dominante cumpriu seu papel, pois através dela, conseguimos entrar no espaço hospitalar, mas esgotou suas possibilidades em pouco tempo, pois não estávamos dispostos a reforçar a ideologia médica, dominante neste campo.

No final dos anos 80 e início dos anos 90, já em outro contexto, a estratégia utilizada foi o de ocupação pelas docentes de cargos de poder nas instituições hospitalares. Esta estratégia nos rendeu muitos frutos, dentre eles a autoria do projeto da sala de parto do Instituto Municipal da Mulher Fernando Magalhães $^{(\mathrm{b})}$, um marco na história da enfermagem obstétrica e da obstetrícia, por ser a primeira vez que, no Rio de Janeiro, o parto hospitalar foi instituído como prática da enfermeira. Este projeto serviu de referência, para que mais tarde, essa prática da enfermeira obstétrica fosse também estendida a outras maternidades vinculadas à Secretaria Municipal de Saúde do Rio de Janeiro, com concepções paradigmáticas bem distintas das do marco inicial.

Já em meados dos anos 90, as circunstâncias nos levaram a atuar no âmbito das políticas públicas, em parceria com a instância central da Secretaria Municipal de Saúde, no projeto de qualificação e ampliação do número de enfermeiras obstétricas da rede para a assistência ao parto e ao pré-natal. Assim, podemos dizer que as principais maternidades do município do Rio de Janeiro contam com a presença da enfermeira obstétrica e que em muitas unidades básicas de saúde, a enfermeira realiza o pré-natal de baixo risco.
Deste modo, vemos que o ciclo se fechou, e que o DEMI, hoje, mantém seus campos de estágio através de uma parceria com todas as instâncias de poder da Secretária Municipal de Saúde, do nível central à enfermeira de plantão em nível local, que na realidade foi nossa aluna.

\section{O fortalecimento da identidade da enfermeira obstétrica}

Ainda neste caminho, optamos por fortalecer a identidade da enfermeira obstétrica através do estudo de sua história. Introduzimos para o curso de graduação uma ampla reflexão sobre a história das mulheres e sobre a história da obstetrícia. Para o curso de Especialização em Enfermagem Obstétrica, criamos uma disciplina de História da Obstetrícia.

A história da obstetrícia é contada a partir da visão de enfermeiras obstétricas e de parteiras, o que as inclui como construtoras e sujeitos importantes do campo obstétrico. Esta história mostra a proximidade social da parteira com a enfermeira, e todo movimento que existiu na sociedade brasileira industrializada para a transformação da parteira em enfermeira. Assim, é possível através do estudo do passado compreender um pouco melhor quem somos, de onde viemos e as origens de nossos conflitos no cotidiano vivido, promovendo prospecções futuras.

\section{CONCLUSÕES}

Este estudo apresentou as estratégias pedagógicas que foram e continuam sendo empregadas no processo de desmedicalização da assistência de enfermagem e no ensino da saúde da mulher da Faculdade de Enfermagem da UERJ. Durante o processo foi necessário dar visibilidade aos mecanismos de dominação simbólica. Para tal, o poder simbólico embutido nas relações entre os médicos e as enfermeiras, tem que ser discutido. Paralelamente foi necessário construir outro referencial e fortalecer a identidade da enfermeira obstétrica, através do conhecimento de seu passado e do fortalecimento e valorização de sua prática social de hoje, visando um amanhã de relações menos opressivas e mais solidárias entre os profissionais e a clientela.
O processo de desmedicalização da assistência à mulher no ensino de enfermagem

\footnotetext{
(b) Instituição pública vinculada à Secretaria Municipal de Saúde do Rio de Janeiro.
}

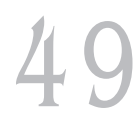

Rev Esc Enferm USP $2004 ; 38(1): 46-50$ 
Octávio Muniz da C Vargens Jane Márcia Progianti

\section{REFERÊNCIAS}

(1) Donnangelo MCF. Saúde e sociedade. $2^{\mathrm{a}}$ ed. São Paulo: Duas Cidades; 1979. p.33.

(2) Cordeiro H. A indústria da saúde no Brasil. $2^{\mathrm{a}}$ ed. Rio de Janeiro: Graal; 1985. p.67.

(3) Illich I. A expropriação da saúde. Rio de Janeiro: Nova Fronteira; 1975. p.43

(4) Bourdieu P. O poder simbólico. 2. ed. Rio de Janeiro: Bertrand Brasil, 1998. p151.
(5) Bourdieu P. O poder simbólico. 2. ed. Rio de Janeiro: Bertrand Brasil, 1998. p.39.

(6) Progianti JM. Parteiras, médicos e enfermeiras: a disputada arte de partejar... [tese] Rio de Janeiro (RJ): Escola de Enfermagem Anna Nery da UFRJ; 2001. p.51-2

(8) Riessman CK. Women and medicalization: a new perspective. Soc Policy. 1983; 14(1): $3-18$. 